\title{
Paradoxical Anxiogenic Response of Juvenile Mice to Fluoxetine
}

\author{
Ji-eun Oh', Bojana Zupan',2, Steven Gross' and Miklos Toth*,1,2 \\ 'Department of Pharmacology, Weill Medical College of Cornell University, New York, NY, USA; ${ }^{2}$ Department of Neuroscience and Neurology \\ and Program in Neuroscience, Weill Medical College of Cornell University, New York, NY, USA
}

\begin{abstract}
Depression, anxiety, and conduct disorders are common in children and adolescents, and selective serotonin reuptake inhibitors (SSRIs) are often used to treat these conditions. Fluoxetine (Prozac) is the first approved SSRI for the treatment of depression in this population. Although it is believed that overall, fluoxetine is effective in child and adolescent psychiatry, there have been reports of specific adverse drug effects, most prominently, suicidality and psychiatric symptoms such as agitation, worsening of depression, and anxiety. Chronic fluoxetine substantially increases brain extracellular 5-HT concentrations, and the juvenile developing brain may respond to supraphysiological 5-HT levels with specific adverse effects not seen or less prominent in adult brain. Using novelty-induced hypophagia, as well as open-field and elevated plus maze tests, we show that both Swiss Webster and C57BI/6 mice, receiving fluoxetine in a clinically relevant dose and during their juvenile age corresponding to child-adolescent periods in humans, exhibit a paradoxical anxiogenic response. The adverse effects of juvenile fluoxetine disappeared upon drug discontinuation and no long-term behavioral consequences were apparent. No adverse effect to chronic fluoxetine was seen in adult mice and a dose-dependent anxiolytic effect developed. These data show that the age of the mice, independently of the strains and tests used in this study, is the determining factor of whether the response to chronic fluoxetine is anxiolytic or anxiogenic. Taken together, the response of the juvenile and adult brain to fluoxetine could be fundamentally different and the juvenile fluoxetine administration mouse model described here may help to identify the mechanism underlying this difference.
\end{abstract}

Neuropsychopharmacology (2009) 34, 2197-2207; doi: I 0.1038/npp.2009.47; published online I 3 May 2009

Keywords: anxiety; fluoxetine; development; mice; behavior; novelty-induced hypophagia

\section{INTRODUCTION}

In the United States, depression affects up to $2.5 \%$ of children and $8.3 \%$ of adolescents (Birmaher et al, 1996; Silverstone, 2004; Wang et al, 2003). The selective serotonin reuptake inhibitor (SSRI), fluoxetine (Prozac), is approved by the Food and Drug Administration for child and adolescent depression (http://www.fda.gov/bbs/topics/ ANSWERS/2003/ANS01187.html). SSRIs are also used in anxiety and conduct disorders, such as separation anxiety and aggression in these populations. Although it is believed that overall, fluoxetine is effective in child and adolescent psychiatry (March et al, 2004), there have been reports on adverse drug effects in these populations, most prominently, suicidality (Hammad et al, 2006) and psychiatric

\footnotetext{
*Correspondence: Professor M Toth, Department of Pharmacology, Weill Medical College of Cornell University, 1300 York Ave, LC519, New York, NY I0021, USA, Tel: + 212746 6247, Fax: + 2127468835 , E-mail: mtoth@med.cornell.edu

Received 7 December 2008; revised 6 April 2009; accepted 7 April 2009
}

effects such as agitation, worsening of depression, and anxiety (March et al, 2004).

Earlier pharmacological and genetic studies indicate that increased 5-HT levels during development result in longterm behavioral and morphological changes in the brain (Ansorge et al, 2004, 2008; Cases et al, 1995, 1996; Maciag et al, 2006; Popa et al, 2008). For example, the pharmacological blockade of the 5-HT transporter (5-HTT) by SSRIs, starting at neonatal or early postnatal life, results in lifelong anxiety and depression-like behavioral abnormalities (Ansorge et al, 2004; Maciag et al, 2006; Popa et al, 2008). As rodents are born less mature compared with humans (Carlson and Willott, 1998; Rauschecker, 1999) (Supplementary Figure 1), these pharmacological studies may be relevant to the clinical use of SSRIs during pregnancy.

As SSRIs are often prescribed for children and adolescents, it is important to know their possible short- and longterm side effects during the child and adolescent periods. We here show that administration of fluoxetine to juvenile mice on two genetic backgrounds, at a dose that produces clinically relevant plasma drug levels, results in an anxiogenic, instead of the expected anxiolytic, effect. However, these adverse effects were reversed upon 
discontinuation of the drug. Interestingly, the paradoxical anxiogenic effect returned on re-exposure to fluoxetine in adulthood in one of the two strains studied. This suggests that although fluoxetine, when administered during the juvenile period, does not cause permanent behavioral changes, it can lead to an abnormal drug response on reexposure later in life.

\section{MATERIALS AND METHODS}

\section{Animals}

Timed pregnant Swiss Webster (SW) and C57Bl/6 (B6) females, approximately 8 days before delivery, were purchased from Taconic (Germantown, NY) and Charles River (Wilmington, MA), respectively. Animals were singlehoused with a 12-h light/dark cycle and with food and water available ad libitum. Male pups were implanted at 2 weeks of age with osmotic minipump Model 1007D (Alzet, Cupertino, CA), providing continuous drug delivery for 7 days. Mice were anesthetized using isoflurane. Minipumps were inserted subcutaneously through midscapular incisions, which were then closed by wound glue. Minipumps were filled with $0.9 \%$ saline solution containing fluoxetine $\mathrm{HCl}$ (Toronto Research, Chemical, North York, ON, Canada) in concentrations delivering 2, 3, and $4 \mathrm{mg} / \mathrm{kg} /$ day drug in a volume of $12 \mu \mathrm{l} /$ day. Controls were implanted with minipumps filled with saline solution. Pumps were removed under anesthesia at 3 weeks of age. Pump implantation/removal did not alter overall behavior in the novelty-induced hypophagia (NIH) test as novel cage latencies to drink between implanted and non-implanted adult mice (16 weeks of age) were not significantly different (Supplementary Figure 2). Following the removal of minipumps at weaning (at 3 weeks of age), delivery of fluoxetine was continued through drinking water. The concentrations of fluoxetine in drinking water, corresponding to $\approx 1.5$ and $3 \mathrm{mg} / \mathrm{kg} /$ day doses in juvenile mice, were 0.015 and $0.03 \mathrm{mg} / \mathrm{ml}$, respectively. Fluoxetine was also administered to adult 8-week-old mice. Drug concentrations in drinking water were $0.03,0.12$, and $0.18 \mathrm{mg} / \mathrm{ml}$ for delivering $\approx 3,12$, and $18 \mathrm{mg} / \mathrm{kg} /$ day drug doses. All animal procedures were approved by the Institutional Animal Care and Use Committee of Weill Cornell Medical College and were performed in accordance with the National Institutes of Health Guidelines for the Care and Use of Laboratory Animals.

\section{Measurements of Fluoxetine and Norfluoxetine in Plasma and Brain}

Fluoxetine and norfluoxetine were extracted from plasma and brain and their levels were determined by HPLC (Millipore Waters 600E with Waters 717 plus Autosampler) as described earlier (Alvarez et al, 1998) using protriptyline as an internal standard (Sigma, St Louis, MO). Blood and brain samples were collected at the middle of the light phase. Standards were made by adding fluoxetine and norfluoxetine (Sigma) to plasma and brain samples from control animals to yield the following concentrations: 0 , $31.25,62.5,125,250,500$, and $1000 \mathrm{ng} / \mathrm{ml}$. A $1.0-\mathrm{ml}$ volume of $0.6 \mathrm{M}$ sodium carbonate-sodium bicarbonate buffer
( $\mathrm{pH}$ 9.0) containing the internal standard protriptyline $(100 \mathrm{ng} / \mathrm{ml})$ was added to either $0.1 \mathrm{ml}$ plasma or weighed brain samples. Brain samples were homogenized using pellet pestles and a motor (Vineland, NJ). After the addition of $7 \mathrm{ml}$ of a mixture of ethyl acetate and $n$-heptane $(20: 80$, $\mathrm{v} / \mathrm{v})$, the vials were capped and vigorously mixed for $1.5 \mathrm{~min}$, then centrifuged at $3000 \mathrm{~g}$ for $10 \mathrm{~min}$. The organic layer was transferred to another tube containing $0.2 \mathrm{ml}$ of acidic phosphate buffer $(0.025 \mathrm{M}$ potassium dihydrogen phosphate adjusted to $\mathrm{pH} 2.3$ with $85 \%$ phosphoric acid), then mixed for $1 \mathrm{~min}$, and centrifuged at $3000 \mathrm{~g}$ for $10 \mathrm{~min}$. The organic layer was discarded, and a 150- $\mu$ l aliquot of the aqueous phase was injected for chromatographic separation. Purospher STAR RP-8 $(5 \mu \mathrm{m})$ column was purchased from Merck (Darmstadt, Germany). The mobile phase was a mixture of an acidic aqueous solution (containing $0.1 \mathrm{ml}$ of perchloric acid and $1.5 \mathrm{~g}$ of tetramethyl-ammonium perchlorate per liter) and acetonitrile $(58: 42, \mathrm{v} / \mathrm{v})$. The filtered mobile phase was used at a flow rate of $1 \mathrm{ml} / \mathrm{min}$. The column effluent was monitored at $228 \mathrm{~nm}$ by using a Waters 474 Scanning Fluorescence Detector. Quantification was performed by calculating the peak-height ratios of each compound to the internal standard.

\section{Behavioral Testing}

Fluoxetine-treated and control (saline pump and no drug in drinking water) juvenile mice were tested in a battery of behavioral tests starting at 5.5 weeks of age. Fluoxetine was administered through the end of the testing period (6.5 weeks). Tests were conducted in the following order separated by 1-2 days of rest: (i) elevated plus maze (EPM), (ii) open-field (OF), (iii) NIH tests, and (iv) forced swim test. Other control and fluoxetine groups, treated during the juvenile period between 2 and 6 weeks of age, were tested at 12 weeks of age, after a 6-week drug-free period to assess the long-term effect of fluoxetine on anxiety. In a parallel experiment, fluoxetine was administered to adult 8-week-old mice and then tested for anxiety (at 12 weeks of age). Different doses were tested with independent groups of animals. Finally, groups of mice, pre-exposed to fluoxetine during the juvenile period- were re-exposed to the drug at 12 weeks of age for 4 weeks and tested between 15 and 16 weeks of age. Some of the SW animals were pre-tested in the NIH test at 12 weeks (before fluoxetine administration), whereas others were not. Pretesting had no apparent effect because home and novel cage latencies at 12 weeks (first test) and at 16 weeks (second test) were not different (Supplementary Figure 3). As pretesting at 12 weeks of age in the NIH test did not alter latency at 16 weeks of age, the pre-tested and non-pre-tested groups were combined.

All tests were performed between 11:00 and 16:00 hours. On test days, animals were transported to the dimly illuminated behavioral laboratory and left undisturbed for at least $1 \mathrm{~h}$ before testing.

NIH test. Mice were single-housed for 3 days before the training began. Then, for 3 consecutive days, mice were presented with diluted $(1: 3$; milk: water) sweetened condensed milk (Carnation). Milk was presented in LM Animal Farms Quick Quench Universal Water Bottle (150 ml, Petco). 
Bottles were positioned through wire cage lids. Home cage testing occurred in the dark on day 4. Each mouse was tested for $10 \mathrm{~min}$ and the latency to drink was recorded. Novel cage testing was on day 5 under bright lighting and by placing the mice into new clean cages of the same dimensions as the home cage but without bedding. Latency to drink was again recorded.

Forced swim test. In the FST, mice were placed in a clear, 21- ${ }^{\circ} \mathrm{C}$ water-filled cylinder (diameter, $20 \mathrm{~cm}$; depth, $13 \mathrm{~cm}$ ) for $6 \mathrm{~min}$. In this test, immobility of the mice is measured between 0 and $6 \mathrm{~min}$.

Elevated plus maze test. EPM was performed using a cross maze with $30 \times 5-\mathrm{cm}$ arms at low-light conditions $(60 \mathrm{~W}$ bulb at $3 \mathrm{~m}$ height at $25 \%$ intensity). Animals were introduced to the middle portion of the maze facing an open arm. Entries into and time spent in the open and closed arms were measured by a video-tracking system (Noldus Information Technology, Wageningen, The Netherlands).

Open-field test. The OF test was performed in a $24 \times 40-\mathrm{cm}$ black box, divided into 12 even-sized $(8 \times 10$ inch $)$ rectangles. The total number of crosses in the OF was recorded at normal light conditions $(60 \mathrm{~W}$ bulb at $3 \mathrm{~m}$ height at $100 \%$ intensity) for $10 \mathrm{~min}$ to measure locomotor activity. The time spent in and the number of entries into the two rectangles at the center of the field were recorded by the video-tracking system to evaluate anxiety.

\section{Proliferation in the Dentate Gyrus}

Six-week-old SW animals received a single injection of $100 \mathrm{mg} / \mathrm{kg} \mathrm{BrdU}$ intraperitoneally (Sigma). Animals were transcardially perfused under deep anesthesia with $4 \%$ paraformaldehyde and sections were processed for immunohistochemistry essentially as described earlier (Tatapudy et al, 2008). Cells, pulse labeled at the $S$ phase, were counted by computer-assisted stereology, a method validated by conventional stereology, as described in our earlier report (Tatapudy et al, 2008).

\section{Statistical Analysis}

One-way ANOVAs with LSD post hoc tests were used in both the behavioral and proliferation studies.

\section{RESULTS}

\section{Experimental Design}

The regional development of the rodent brain proceeds on a timeline of days and weeks $v s$ to months and years in humans (Supplementary Figure 1). Overall, the mouse brain is relatively less mature than the human at birth as eye opening and the onset of hearing occurs only during the second postnatal week in mice (Carlson and Willott, 1998; Rauschecker, 1999). Mouse reaches maturity around 8 weeks of age. To capture the time frame and developmental events corresponding to the approximate child and adolescent periods in human, we administered fluoxetine to mice from 2 to 6 weeks of age (referred to as juvenile age throughout this paper) and then assessed anxiety-related behavior. Fluoxetine was administered throughout the testing period.

\section{Continuous Administration of Fluoxetine Provides Clinically Relevant Steady-State Plasma Drug Levels in Juvenile Mice}

The half-life of fluoxetine and its metabolite, norfluoxetine, in mice is shorter than that in humans $\left(t_{1 / 2}: 8\right.$ and $16 \mathrm{~h}$, respectively); therefore, the drug was administered continuously from 2 weeks of age until weaning age (3 weeks of age) by osmotic minipumps followed by the delivery of the drug through drinking water. First, we determined the fluoxetine dose that provides a clinically relevant plasma drug and metabolite level in SW mice (Figure 1). As there are significant individual differences in the metabolism of fluoxetine in human adults, drug levels show a broad range from a low 50-60 to a high $400-500 \mathrm{ng} / \mathrm{ml}$, though the levels can be even higher in some individuals (Alvarez et al, 1998; Amsterdam et al, 1997; Lundmark et al, 2001; Orsulak et al, 1988). Steady-state levels in children and adolescents are similar to adult values (Wilens et al, 2002). As during the first week of treatment, relatively high norfluoxetine concentrations were associated with relatively low fluoxetine levels (norfluoxetine/fluoxetine ratio $\approx 7$; Figure 1a and Supplementary Figure 4), $1.5-3 \mathrm{mg} / \mathrm{kg} /$ day drug provided low fluoxetine and median norfluoxetine plasma levels, respectively (Figure 1a and b). Once mice were weaned and the drug was delivered through drinking water, $3 \mathrm{mg} / \mathrm{kg} /$ day dose provided low-to-intermediate fluoxetine and norfluoxetine plasma levels (Figure 1c). Also, the norfluoxetine/fluoxetine ratio was 2-3, closer to the 1.3-1.5 value measured in humans (Lundmark et al, 2001) (Supplementary Figure 4).

The levels of both fluoxetine and norfluoxetine were approximately 25 times higher in the brain than in the plasma in SW mice, indicating a substantial drug accumulation in the CNS (Figure 1d and e). This is consistent with an earlier study that measured $\approx 20$ times higher fluoxetine and norfluoxetine levels in brain as compared with serum (Henry et al, 2005). High brain drug levels are likely due to the lipophilicity of fluoxetine and norfluoxetine (Bolo et al, 2000; Strauss et al, 2002).

The plasma and brain fluoxetine levels, measured in SW mice at the $3 \mathrm{mg} / \mathrm{kg} / \mathrm{day}$ dose, are adequate for the development of therapeutic effects in humans and correspond to $76-85 \%$ 5-HTT occupancy (in various brain regions) (Meyer et al, 2004). Mice have a similar relationship between fluoxetine plasma levels and 5-HTT occupancy/5-HTT-binding activity (Hirano et al, 2005).

\section{Juvenile Mice Respond to Fluoxetine with a Paradoxical Anxiogenic Effect}

SSRIs are effective at alleviating both anxiety and depression symptoms present in comorbid anxiety-depression disorders. Yet, it has been a challenge to reproduce these anxiolytic, and especially the antidepressant, effects of SSRIs in animals. One particular problem is the time course of the response to the drug treatment: antidepressants 

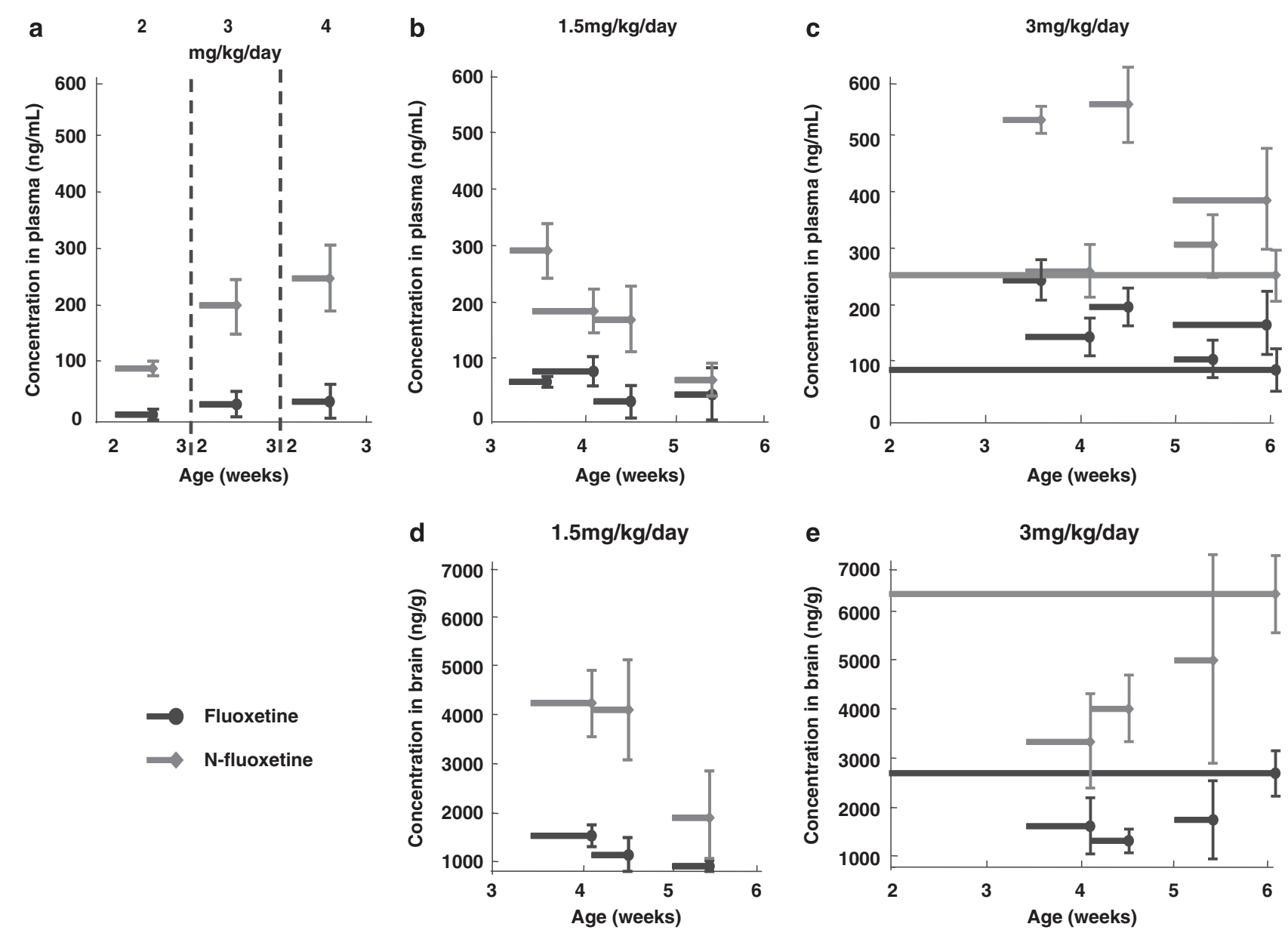

Figure I Plasma and brain levels of fluoxetine and its metabolite, norfluoxetine, following administration through osmotic minipumps between 2 and 3 weeks of age and through drinking water from weaning at 3 to 6 weeks of age. In contrast to humans, neither fluoxetine nor norfluoxetine shows an appreciable day-to-day accumulation in mice (due to the relatively short half-life, see Results); therefore, we first measured levels following short, 3-4-day administration periods distributed throughout the juvenile period, then measured levels following administration throughout the entire 2-6-week period. Horizontal lines with error bars representing SE indicate the length of the administration and the mean drug levels (3-4 animals per time point). (a) The $3-\mathrm{mg} / \mathrm{kg} /$ day dose provided low-to-medium clinical plasma levels of total fluoxetine and norfluoxetine ( $230 \mathrm{ng} / \mathrm{ml}$ total). (c) Once mice were weaned and the drug was delivered through drinking water for 3-4 days, the same $3 \mathrm{mg} / \mathrm{kg} /$ day dose provided I 00-250 and 250-570 ng/ml fluoxetine and norfluoxetine plasma levels, respectively. When fluoxetine was continuously administered for 4 weeks, the endpoint values (at 6 weeks of age) were $\sim 100 \mathrm{ng} / \mathrm{ml}$ for the parent drug and $\sim 250 \mathrm{ng} / \mathrm{ml}$ for the metabolite, both at midrange clinically relevant levels. (b) A lower $1.5 \mathrm{mg} / \mathrm{kg} /$ day dose was also tested, but the corresponding plasma drug levels, although appropriate initially, became low toward the sixth postnatal week, which made the use of this dose less desirable. ( $d$ and e) Brain levels are approximately 25 times higher than plasma levels.

require chronic administration in humans but most of the animal tests detect the effect of acute treatments. Also, there is no current measure of rodent 'mood,' and therefore, the antidepressant effect of SSRIs is difficult to assess. Some recent data indicate, however, that the anxiolytic effect of chronic SSRIs, including fluoxetine, may be detectable in rodents (Dulawa and Hen, 2005; Dulawa et al, 2004; Rygula et al, 2006; Zazpe et al, 2007). Indeed, the NIH test is sensitive to the chronic, but not the acute, administration of various antidepressants including fluoxetine in adult mice (Dulawa and Hen, 2005; Dulawa et al, 2004). The NIH test measures avoidance to approach and consume palatable food (sweetened milk) in a stressful environment. Higher approach latency indicates greater avoidance, which reflects a higher anxiety level. Chronic SSRI treatments reduce this approach latency.

Surprisingly, $3 \mathrm{mg} / \mathrm{kg} /$ day continuous administration of fluoxetine during the juvenile period resulted in a significant increase in the latency to drink in a novel cage at 6 weeks of age in SW mice (treatment: $F_{1,58}=9.60$, $p=0.0029 ; N=31$ and 29), indicating an anxiogenic, instead of the expected, anxiolytic effect (Figure 2a). Latency to drink in the home cage was not different between control (saline/water) and fluoxetine-treated SW animals $\left(\mathrm{F}_{1,58}=0.94, p=0.336\right.$; Figure $\left.2 \mathrm{a}\right)$, indicating no baseline difference between the groups and that the increased latency of fluoxetine-treated mice in the novel cage was not the result of decreased motivation or increased anhedonia. Another measure of anxiety, the difference in approach latency between the novel cage and the home cage, was also significantly greater in the fluoxetine-treated group compared with saline-treated controls (control: $254.80 \pm 43.79 \mathrm{~s} v s$ fluoxetine: $389.27 \pm 45.27 \mathrm{~s}$, mean $\pm \mathrm{SD}$; $\left.\mathrm{F}_{1,58}=4.55, p=0.037\right)$.

To confirm the surprising paradoxical effect produced by juvenile fluoxetine administration in SW mice, we repeated this experiment with the relatively less 'anxious' B6 mice in $\mathrm{NIH}$ (latency to drink in novel environment at 6 weeks of 
a

NIH (SW)
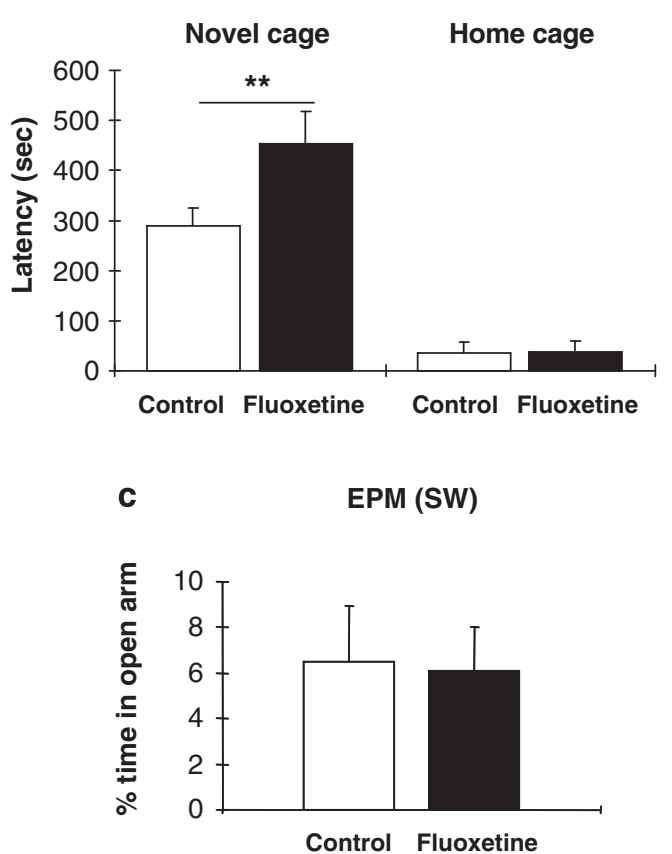

e

OF (SW)

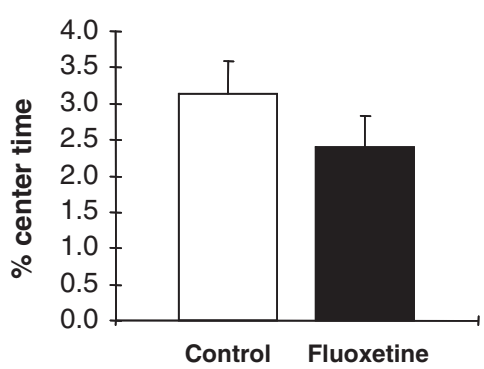

g

FST (SW)

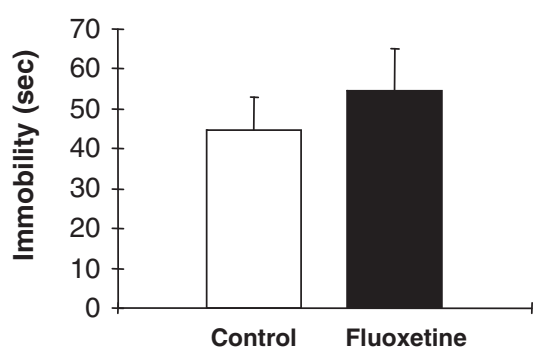

b

NIH (B6)
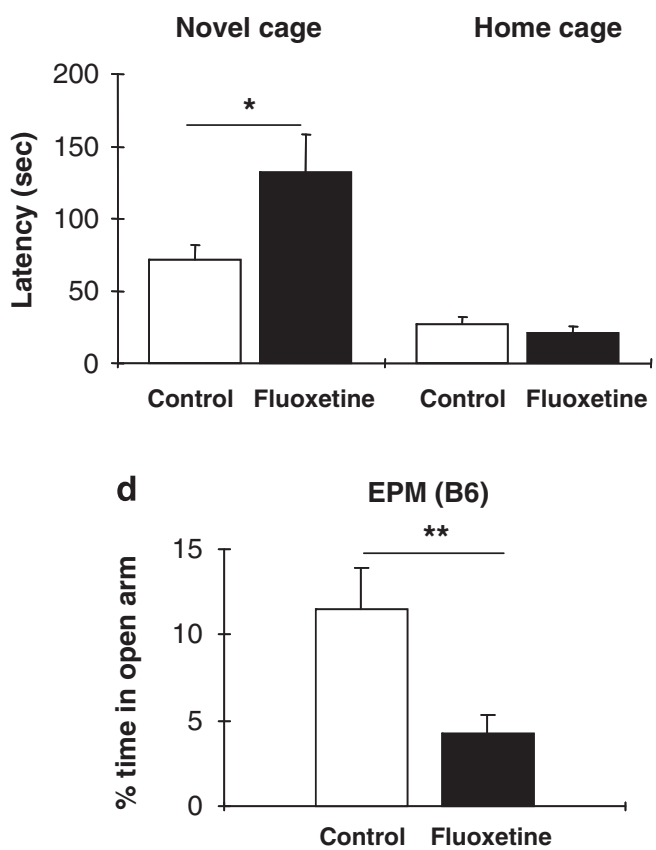

f OF (B6)

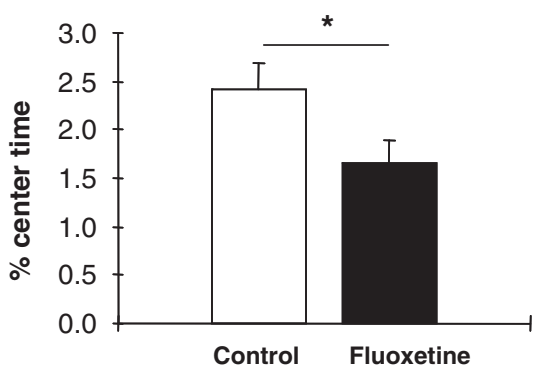

h

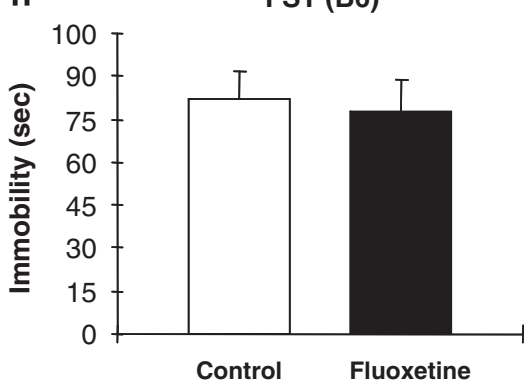

Figure 2 Paradoxical anxiogenic effect of fluoxetine in 6-week-old SW (a, c, e, and g) and B6 (b, d, f, and h) mice treated with 3 mg/kg/day for $\sim 4$ weeks during the juvenile period as measured in the NIH (a and b), EPM ( $c$ and d), OF (e and f), and FST ( $g$ and $h$ ) tests at the end of the treatment (ANOVA with LSD post hoc test: $* p<0.05$; ${ }^{*} p<0.0$ l).

age: SW: $290.06 \pm 26.57 \mathrm{~s} ; \mathrm{B} 6: 71.64 \pm 25.37 \mathrm{~s} ; \mathrm{F}_{1,63}=35.33$, $p<0.0000001$; Figure $2 \mathrm{a}$ and $\mathrm{b})$. Similar to SW mice, juvenile B6 mice showed an increase in novel cage latency to $3 \mathrm{mg} / \mathrm{kg} /$ day fluoxetine (treatment: $\mathrm{F}_{1,68}=4.35, p=0.041$; $N=34$ and 36) (Figure 2b). Similar to that in the SW groups, no difference was seen in home cage latencies between the control and fluoxetine-treated B6 animals $\left(\mathrm{F}_{1,68}=0.80, p=0.373\right.$; Figure $\left.2 \mathrm{~b}\right)$.

Two other behavioral tests, the EPM and OF, are usually insensitive to chronic fluoxetine administered in adulthood
(Borsini et al, 2002; Prut and Belzung, 2003), but the B6 strain exhibits an anxiolytic response in the OF test to chronic fluoxetine treatment (Chen et al, 2006). A strain difference was also reflected in how SW and B6 mice respond to juvenile fluoxetine treatment. Although the administration of $3 \mathrm{mg} / \mathrm{kg} /$ day fluoxetine in juvenile $\mathrm{SW}$ mice produced no behavioral changes in either test (Figure $2 \mathrm{c}$ and e), B6 mice exhibited a paradoxical reduction in time spent in the open arm of $\operatorname{EPM}\left(\mathrm{F}_{1,58}=7.87, p=0.007\right.$; Figure $2 \mathrm{~d})$ and in the center of the $\mathrm{OF}\left(\mathrm{F}_{1,58}=4.48\right.$, 
$p=0.038$; Figure $2 \mathrm{f}$ ). Total activity of fluoxetine-treated B6 mice was not different from that of saline-treated animals in the EPM $\left(F_{1,58}=0.22, p=0.637\right)$. However, total locomotor activity of these mice was reduced in OF (saline: $3102 \pm 85 \mathrm{~cm}, \quad N=34$; fluoxetine: $2656 \pm 83 \mathrm{~cm}, \quad N=36$; mean $\left.\pm \mathrm{SD} ; \mathrm{F}_{1,68}=13.94, p=0.0004\right)$. Reduced activity in OF can also be interpreted as increased anxiety because suppression of general locomotor activity represented one of the dimensions of anxiety in a large mouse QTL study (Henderson et al, 2004). Also, 5-HT1A receptor knockout mice exhibit not only anxiety in EPM and OF but also reduced locomotor activity in OF (Gross et al, 2002).

The FST is generally used to detect the antidepressant-like effect of fluoxetine and other SSRIs following acute administration. All major groups of antidepressants reduce immobility time in this test. However, FST is not a good predictor of antidepressant effect when clinically more relevant chronic administration conditions are used. Indeed, only one (BALB/ c) of the four tested $(\mathrm{B} 6,129 \mathrm{SvEv}$, and DBA/2) mouse strains responded to a 3-week-long drug treatment (Dulawa et al, 2004). When juvenile SW and B6 mice following chronic fluoxetine administration were tested in FST, we saw no significant behavioral changes ( $\mathrm{SW}: \mathrm{F}_{1,56}=0.05, p=0.822$; B6: $\mathrm{F}_{1,50}=0.09, p=0.758$; Figure $2 \mathrm{~g}$ and $\mathrm{h}$ ).

\section{Juvenile Fluoxetine Treatment has no Effect on Neuronal Proliferation in the Dentate Gyrus}

Fluoxetine and other antidepressants increase neuronal proliferation in the adult dentate gyrus (Malberg et al, 2000), whereas anxiety induced by stress and depressionlike conditions in animal models is associated with reduced dentate proliferation (Czeh et al, 2001; Gould et al, 2000). Some studies, however, dispute these links (Bessa et al, 2008; Holick et al, 2008; Reif et al, 2006; Vollmayr et al, 2003). The increased anxiety of juvenile fluoxetine-treated mice was not associated with a significant reduction in proliferation at 6 weeks of age as measured by the incorporation of BrdU to cellular DNA with 2-h survival time (BrdU-positive cell number per section: control: $7.72 \pm 0.98$ and fluoxetine: $7.06 \pm 0.98 ; t=0.47, p=0.64$, 8-10 sections per animal, six animals per group).

\section{Juvenile Fluoxetine Treatment has no Lasting Effect on Anxiety-Related Behavior}

Earlier data showed that in utero and early postnatal exposure to fluoxetine results in lasting behavioral abnormalities, including increased anxiety (Ansorge et al, 2004; Noorlander et al, 2008; Popa et al, 2008). This raised the possibility that the increased anxiety of juvenile mice at 6 weeks of age in our experiments may not be an adverse drug effect but rather the manifestation of a permanent anxiety phenotype. To differentiate between these scenarios, SW and $\mathrm{B} 6$ mice were exposed to fluoxetine in their juvenile age (2-6 weeks of age) and then withdrawn from the drug and tested 6 weeks later (at 12 weeks of age) in NIH test, EPM, $\mathrm{OF}$, and FST. None of the tests indicated anxiety or behavioral change (Figure $3 \mathrm{a}-\mathrm{h}$ ), suggesting that juvenile administration of fluoxetine does not elicit permanent anxiety-like behaviors in SW or B6 mice and that the increased anxiety response of juvenile mice of both strains in the NIH test, as well as of the B6 in the EPM and OF tests, was likely an adverse drug response.

\section{Adult Mice Respond to Fluoxetine with Anxiolytic Effects}

As the effect of fluoxetine administration in SW and B6 juvenile mice was anxiogenic, we assessed if the drug elicits the expected anxiolytic effect in adults. Doses higher than $3 \mathrm{mg} / \mathrm{kg} /$ day were also tested; fluoxetine in the $10-25 \mathrm{mg} / \mathrm{kg} /$ day range has been used to achieve an anxiolytic/ antidepressant effect in adult mice (Dulawa and Hen, 2005). As shown in Figure $4,18 \mathrm{mg} / \mathrm{kg} /$ day fluoxetine administered for 3-4 weeks starting at 8 weeks of age resulted in an anxiolytic effect in SW mice. On the other hand, $3 \mathrm{mg} / \mathrm{kg} /$ day (that produced anxiety in juvenile mice), as well as an intermediate $12 \mathrm{mg} / \mathrm{kg} /$ day dose, resulted in no detectable effect in adult SW mice, indicating that once the brain fully develops, these lower drug doses have no adverse effects in this strain (Figure 4). As reported earlier (Chen et al, 2006), C57Bl/6 mice also exhibit an anxiolytic response in the NIH test following 3 weeks of $18 \mathrm{mg} / \mathrm{kg} /$ day fluoxetine administration starting at 10-12 weeks of age (the current studies and those by Chen et al (2006) were performed by using the same method and equipment; see Materials and methods).

Plasma drug levels in juvenile and adult SW mice following the $3 \mathrm{mg} / \mathrm{kg} /$ day dose were comparable (juvenile: Figure 1c; adult: fluoxetine $73.2 \pm 6.3 \mathrm{ng} / \mathrm{ml}$, norfluoxetine $230.5 \pm 21.3 \mathrm{ng} / \mathrm{ml}$, mean $\pm \mathrm{SD} ; N=5$ per group). The higher $12 \mathrm{mg} / \mathrm{kg} /$ day (fluoxetine $840.4 \pm 116.2 \mathrm{ng} / \mathrm{ml}$, norfluoxetine $1458.7 \pm 268.2 \mathrm{ng} / \mathrm{ml}$, mean $\pm \mathrm{SD} ; N=5$ per group) and $18 \mathrm{mg} / \mathrm{kg} /$ day doses produce plasma concentrations at the highest range measured in patients undergoing treatment. Similarly, high levels were detected at $18 \mathrm{mg} / \mathrm{kg}$ in $\mathrm{B} 6$ mice as well (fluoxetine $958.8 \pm 118.7 \mathrm{ng} / \mathrm{ml}$, norfluoxetine $2050.9 \pm 233.5 \mathrm{ng} / \mathrm{ml} ; N=5$ per group). These data indicate that the juvenile, but not the adult, brain is sensitive to clinically relevant drug concentrations in mice and that only very high drug levels elicit anxiolytic effects in adult mice in the NIH test. As a much lower drug level was sufficient to elicit the paradoxical anxiogenic response, the anxiogenic and anxiolytic effects of fluoxetine in juvenile and adult mice are probably mediated by different mechanisms.

In the EPM and OF tests, adult SW mice did not show an anxiolytic effect to $18 \mathrm{mg} / \mathrm{kg} /$ day fluoxetine (Supplementary Figure 5). In contrast, B6 mice exhibit reduced anxiety to $18 \mathrm{mg} / \mathrm{kg} /$ day fluoxetine in the OF test (Chen et al, 2006). This strain-dependent pattern of adult response mirrors the juvenile pattern, that is B6 responds though the juvenile and adult responses are opposite. whereas SW does not respond in either age (Figures 2 and 4, summarized in Table 1).

\section{The Paradoxical Anxiogenic Response of Juvenile Mice to Fluoxetine is Recapitulated on Re-Exposure in} Adulthood in SW but not in B6 Mice

Although juvenile exposure to fluoxetine had no longlasting effects on baseline anxiety and depression-like behavior in adult mice, it could have altered drug response permanently. To test this possibility, SW and B6 mice treated during the juvenile period (2-6 weeks) were 
a

NIH (SW)

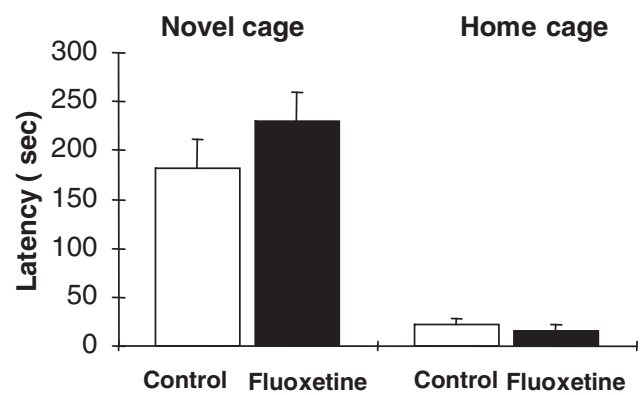

C

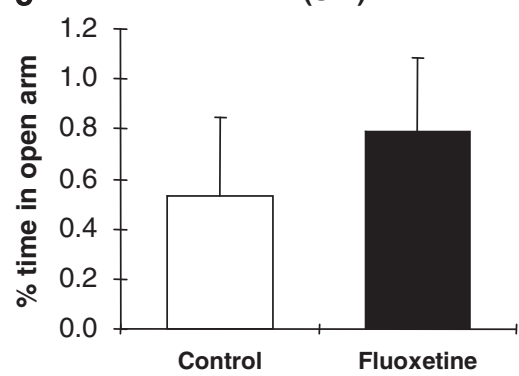

e OF (SW)

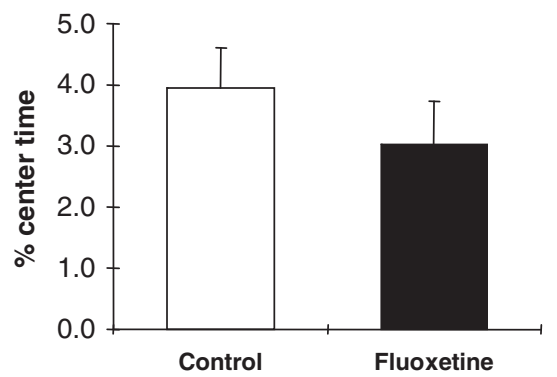

g

FST (SW)

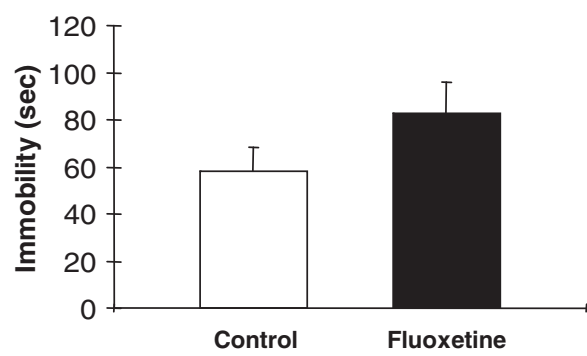

b

NIH (B6)

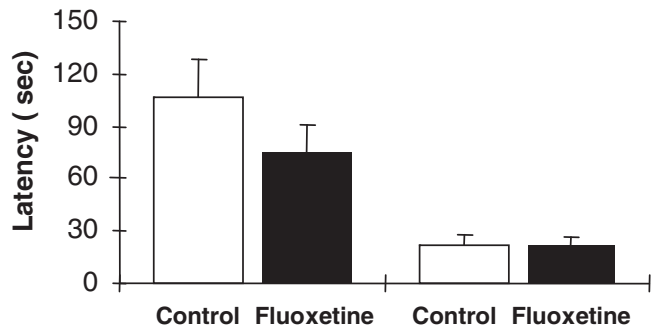

d $\quad$ EPM (B6)

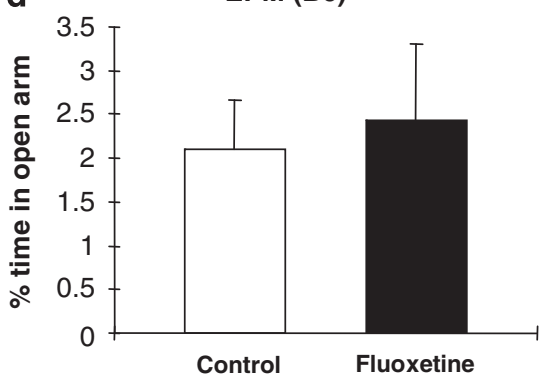

f

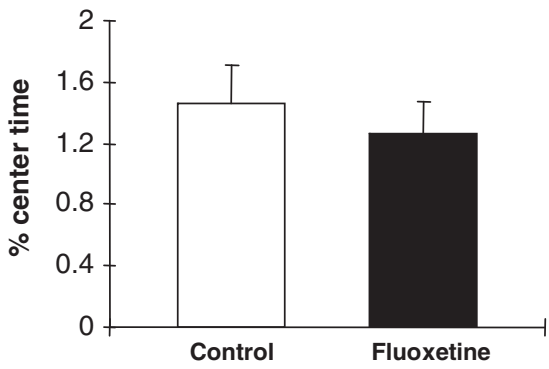

h

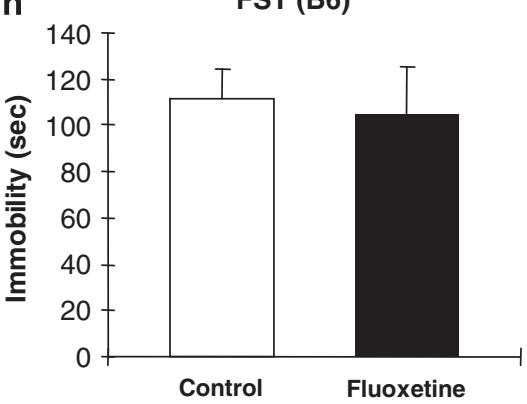

Figure 3 Behavior of 12 -week-old SW (a, c, e, and g) and B6 (b, d, f, and h) mice following juvenile (between 2 and 6 weeks of age) fluoxetine treatment $(3 \mathrm{mg} / \mathrm{kg} /$ day) and a 6-week drug-free period. (a and b) The anxiogenic effect of fluoxetine seen at 6 weeks of age in SW and B6 mice in the NIH test is no longer detectable at 12 weeks of age. (c-h) Other behavioral parameters are also normal in adult mice exposed to fluoxetine during the juvenile period.

re-exposed as adults (after a 6-week drug-free period) to 3 or $12 \mathrm{mg} / \mathrm{kg} /$ day fluoxetine for 4 weeks (12-16 weeks) (Figure 5). Although $3 \mathrm{mg} / \mathrm{kg} /$ day fluoxetine had no effect (Supplementary Figure 6), re-exposure to $12 \mathrm{mg} / \mathrm{kg} / \mathrm{day}$ resulted in an increase in novel cage latency in SW mice (one-way ANOVA: $\mathrm{F}_{3,30}=3.17, p=0.038$; post hoc analysis: Fluoxetine $_{\text {juvenile }} \rightarrow$ Fluoxetine $_{\text {adult }}$ vs Control $_{\text {juvenile }} \rightarrow$ Control $_{\text {adult }}, p=0.0356$ and $\mathrm{F} \rightarrow \mathrm{F}$ vs $\mathrm{C} \rightarrow \mathrm{F}, p=0.006,8-10$ animals per group; Figure 5a). No change was seen in $\mathrm{F} \rightarrow \mathrm{C}$ as compared with $\mathrm{C} \rightarrow \mathrm{C}$ mice, in agreement with earlier data (Figure 3a) showing that juvenile fluoxetine treatment has no long-lasting effect on behavior in the NIH test in the SW mice. Latencies in home cage were not significantly changed in any group compared with the $\mathrm{C} \rightarrow \mathrm{C}$ group (oneway ANOVA, $\mathrm{F}_{3,30}=1.38, p=0.267$ ), indicating that home cage behavior is not altered by the treatment (Figure $5 \mathrm{a}$ ). In contrast to SW mice, re-exposure of $\mathrm{B} 6$ mice to $12 \mathrm{mg} / \mathrm{kg} /$ day fluoxetine resulted in no behavioral effect in $\mathrm{NIH}$ test (Figure 5b). These B6 mice showed no behavioral changes in EPM and OF either (Figure 5c-d) or in FST (Supplemen- 


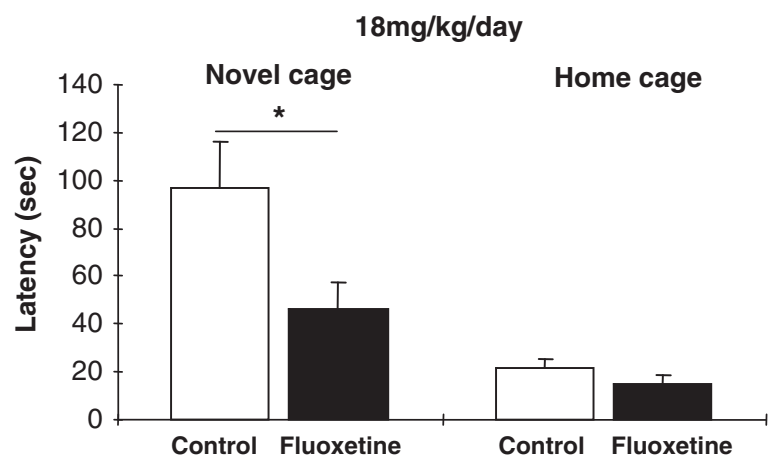

$12 \mathrm{mg} / \mathrm{kg} / \mathrm{day}$
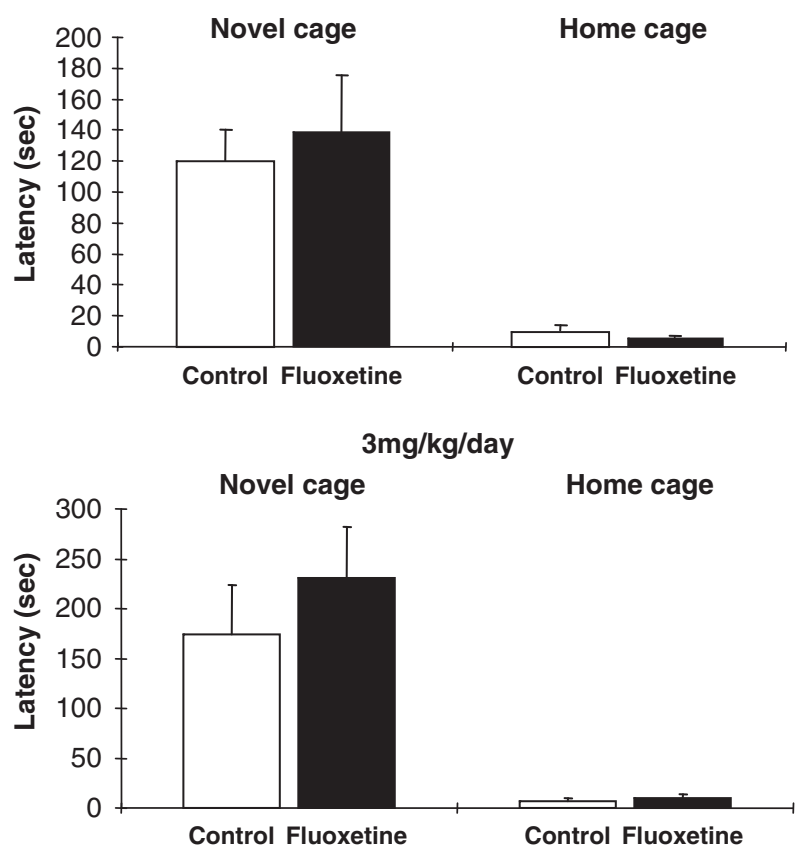

Figure 4 Four weeks of chronic fluoxetine administration produces an anxiolytic response in adult SW mice in the $\mathrm{NIH}$ test. However, only the relatively high $18 \mathrm{mg} / \mathrm{kg} /$ day dose was effective, whereas the 3 and $12 \mathrm{mg} /$ $\mathrm{kg} /$ day doses resulted in no change in novel cage latencies (ANOVA with LSD post hoc test: $* p<0.05$ )

tary Figure 7) (SW mice responded to neither juvenile nor adult administration of fluoxetine in EPM and OF, see Figures 2 and 3; thus, there was no behavior to recapitulate and the effect of fluoxetine re-exposure was not assessed in SW mice in these tests). Taken together, these data suggest that the juvenile low fluoxetine exposure led to permanent changes in the antidepressant drug response in the NIH test in SW but not in B6 mice.

\section{DISCUSSION}

Both genetic (inactivation of MAO-A and 5-HTT) and pharmacological (administration of SSRIs) experiments indicate that excessive levels of 5-HT during prenatal and early postnatal life in rodents have long-term morphological and behavioral consequences (Ansorge et al, 2004, 2008; Cases et al, 1995, 1996; Maciag et al, 2006; Popa et al, 2008). Indeed, fluoxetine administration between E8 and E18 as well as from P4 to P20 resulted in persistent anxiety and
Table I Anxiolytic vs Anxiogenic Response to Chronic Fluoxetine is Age Dependent Across Two Strains and Various Behavioral Tests

\begin{tabular}{|c|c|c|c|c|}
\hline \multirow{2}{*}{$\begin{array}{c}\text { Behavioral } \\
\text { test }\end{array}$} & \multicolumn{2}{|c|}{ Adult } & \multicolumn{2}{|c|}{ Juvenile } \\
\hline & SW & B6 & SW & B6 \\
\hline \multicolumn{5}{|l|}{ NIH } \\
\hline EPM & $\Longleftrightarrow$ & $N D^{b}$ & $\Longleftrightarrow$ & $\hat{\mathbf{1}}$ \\
\hline OF & $\Longleftrightarrow$ & $\prod^{a}$ & $\Longleftrightarrow$ & $\boldsymbol{\uparrow}$ \\
\hline \multicolumn{5}{|c|}{$\sqrt{ }$ reduced and $\mathbf{\uparrow}$ increased anxiety-like behavior } \\
\hline \multicolumn{5}{|c|}{ a Chen et al., 2006} \\
\hline \multicolumn{5}{|c|}{$\mathrm{b}$ not determined } \\
\hline
\end{tabular}

depression-like behaviors (Ansorge et al, 2004; Noorlander et al, 2008). Owing to the early onset of the 5-HT effect in these experiments and because rodents are born less matured compared with humans (eg, eye opening and hearing onset are on the second postnatal week in rodents) (Carlson and Willott, 1998; Rauschecker, 1999), these pharmacological and genetic studies may not answer the question of whether SSRIs have short- or long-term adverse effects in children and adolescents. To match the developmental time frame corresponding to the child and adolescent periods more precisely in mice, fluoxetine in our experiments was administered between 2 and 6 weeks of age in mice.

The main finding of our study is that chronic fluoxetine when administered to juvenile mice elicits an anxiogenic effect, whereas in adult mice the drug results in the expected anxiolytic effect. Indeed, both SW and B6 mice at juvenile age exhibit increased anxiety to chronic fluoxetine in the NIH test, whereas as adults they respond to the drug with an anxiolytic effect (Table 1). Although response to chronic fluoxetine in the EPM and OF is strain specific, when there is an anxiolytic effect in adults, there is invariably an anxiogenic response in juvenile mice (Table 1). Therefore, the age of the mice, independently of the strain and the test used in our experiments, is the primary determining factor of whether the response to chronic fluoxetine is anxiolytic or anxiogenic.

Adverse effects including anxiety and depressed mood to fluoxetine have also been observed in children and adolescents (March et al, 2004). Although extrapolating our results to the pediatric/adolescent use of fluoxetine may not be straightforward, the abnormal response of juvenile mice to fluoxetine may suggest that the antidepressant effect of the drug may be counteracted by anxiety-promoting adverse effects, which could reduce the overall therapeutic efficacy of the drug. Taken together, administration of fluoxetine between 2 and 6 weeks of age in mice reproduces some of the adverse effects of the drug described in human studies, and the juvenile fluoxetine administration model may be suitable to study the origin and nature of adverse fluoxetine effects specific for the child and adolescent periods. 
a NIH (SW)

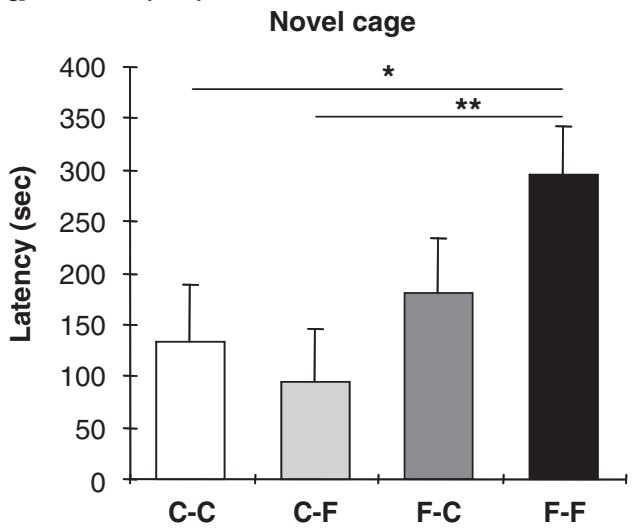

b NIH (B6)

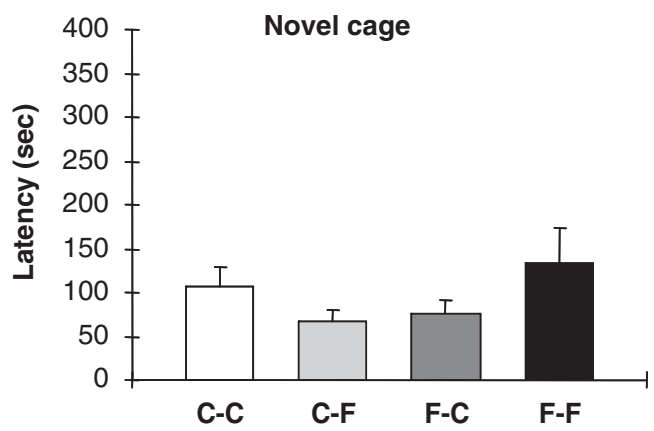

C

EPM (B6)

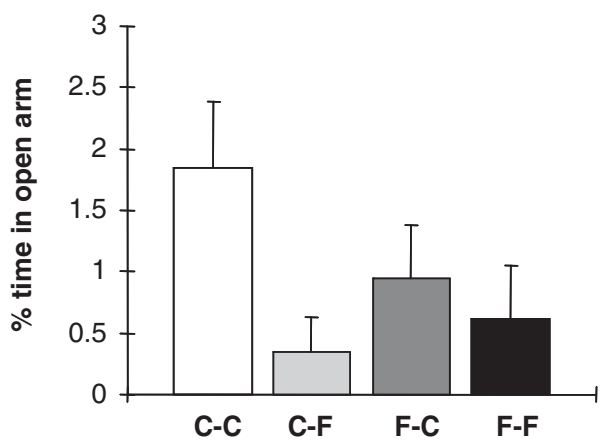

Home cage
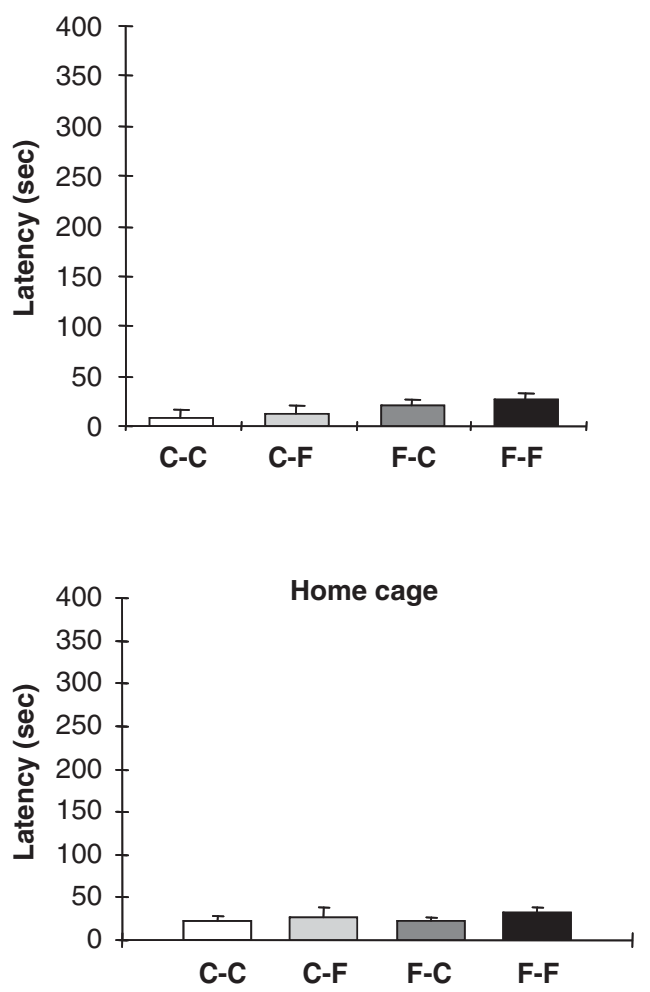

d OF (B6)

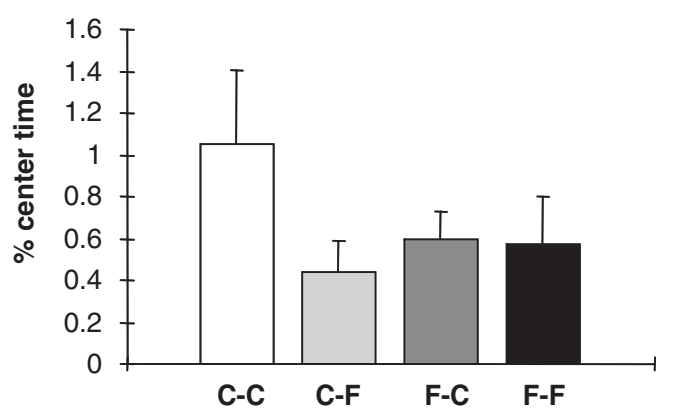

Figure $\mathbf{5}$ The anxiogenic effect of fluoxetine produced in juvenile animals is recapitulated on re-exposure to the drug in adulthood in the $\mathrm{NIH}$ test in $\mathrm{SW}$, but not B6 mice. (a) Re-administration of $12 \mathrm{mg} / \mathrm{kg} /$ day dose for 4 weeks (I2-16 weeks of age) in the SW mice resulted in increased approach latencies in the novel cage in $\mathrm{F} \rightarrow \mathrm{F}$ compared with $\mathrm{C} \rightarrow \mathrm{C}$ and $\mathrm{C} \rightarrow \mathrm{F}$ treatment groups (ANOVA with LSD post hoc test: * $p<0.05$; ** $p<0.0$ ). (b) Re-exposure to $12 \mathrm{mg} / \mathrm{kg} /$ day fluoxetine produced no change in B6 mice in the $\mathrm{NIH}$ test. (c and d) No fluoxetine effect in EPM and OF in B6 mice either. CC: ${\text { Control juvenile } \rightarrow \text { Control }_{\text {adult, }} \text { CF: Control }}_{\text {juvenile }} \rightarrow$ Fluoxetine $_{\text {adult, }}$ FC: Fluoxetine juvenile $\rightarrow$ Control $_{\text {adultt }}$ FF: Fluoxetine juvenile $\rightarrow$ Fluoxetine $_{\text {adult. }}$

Although the anxiogenic effect of chronic fluoxetine in juvenile mice was apparent at $3 \mathrm{mg} / \mathrm{kg} / \mathrm{day}$ in both $\mathrm{SW}$ and B6, the anxiolytic effect of the drug was detectable only at $18 \mathrm{mg} / \mathrm{kg} /$ day dose in these strains. The $3 \mathrm{mg} / \mathrm{kg} /$ day dose, whether in juvenile or adult mice, resulted in therapeutically relevant plasma drug levels $(100-300 \mathrm{ng} / \mathrm{ml}$ fluoxetinenorfluoxetine), indicating that the developing brain may be particularly sensitive to the adverse effects of fluoxetine. Data show that $20 \mathrm{mg} /$ day chronic fluoxetine administration corresponds to about $100 \mathrm{ng} / \mathrm{ml}$ drug plasma level and 76-85\% 5-HTT occupancy in human. This occupancy level is sufficient for the development of a therapeutic effect (Meyer et al, 2004). Mice have a similar relationship between fluoxetine plasma levels and 5-HTT occupancy/
5-HTT-binding activity (Hirano et al, 2005). The sensitivity of juvenile mouse brain to the adverse effects of fluoxetine is consistent with the notion that children and adolescents have a different adverse effect profile to SSRIs than do adults. The $18 \mathrm{mg} / \mathrm{kg} / \mathrm{day}$ dose that is required for the development of the anxiolytic activity in adult mice corresponds to very high human plasma levels that are well over the normal therapeutic level. This may indicate a species difference in the anxiolytic effect of fluoxetine in adults.

Anxiety has been associated with reduced proliferation in the dentate gyrus of adult rodents (Gould et al, 2000). There was no change in neuronal proliferation in fluoxetinetreated juvenile mice exhibiting anxiety in our experiments. Although it is not clear whether this was due to the low, 
albeit, therapeutically relevant fluoxetine level, the age of animals or some other factors, our data show that the anxiety phenotype of fluoxetine-treated juvenile mice may not be linked to a neuronal proliferation defect in the dentate gyrus.

In contrast to the studies that targeted an earlier developmental period (Ansorge et al, 2004; Noorlander et al, 2008), our studies with juvenile mice showed no permanent anxiety or depression-like phenotypes in either B6 or SW mice. A similar study with fluoxetine administration between P21 and P49 showed no long-term behavioral effects either (Norcross et al, 2008). The anxiety phenotype of fluoxetine-treated mice at 6 weeks of age that disappeared after a 6-week drug-free period is also consistent with the reversibility of adverse drug events to dose reduction or treatment discontinuation in children and adolescents. In summary, our study indicates that in contrast to earlier assertions, fluoxetine administration during postnatal development in mice, which corresponds to the child and adolescent periods, is not likely to cause permanent behavioral alterations.

An unexpected finding in our study is that re-exposure to fluoxetine of adult mice, treated earlier with fluoxetine during the juvenile period, recapitulated the paradoxical anxiogenic effect of the drug. However, this effect was detected only in SW mice, indicating that this phenomenon is strain dependent. Nevertheless, the 'recall' of the anxiogenic response upon re-exposure could indicate permanent changes in the antidepressant drug response in this strain. If similar effects occur in the human population, our data would suggest that exposure of susceptible individuals to fluoxetine in adolescence may render them less responsive to future drug treatment.

\section{DISCLOSURE/CONFLICT OF INTEREST}

The authors declare no conflict of interest.

\section{ACKNOWLEDGEMENTS}

We thank Sandra Bruening and Charles Inturrisi for their help in the fluoxetine measurements and pharmacokinetic studies, respectively. We thank Noel Yan Ki Chan for her help with the NIH tests. We also thank Dr. Kevin Bath and Francis Lee for providing us plasma from B6 mice chronically treated with fluoxetine. Finally, we thank Sonali Tatapudy for counting BrdU-positive cells. The work was supported by NIMH 1R21MH072820 and 5R01MH058669 to MT.

\section{REFERENCES}

Alvarez JC, Bothua D, Collignon I, Advenier C, Spreux-Varoquaux O (1998). Determination of fluoxetine and its metabolite norfluoxetine in serum and brain areas using high-performance liquid chromatography with ultraviolet detection. J Chromatogr B Biomed Sci Appl 707: 175-180.

Amsterdam JD, Fawcett J, Quitkin FM, Reimherr FW, Rosenbaum JF, Michelson D et al (1997). Fluoxetine and norfluoxetine plasma concentrations in major depression: a multicenter study. Am J Psychiatry 154: 963-969.
Ansorge MS, Morelli E, Gingrich JA (2008). Inhibition of serotonin but not norepinephrine transport during development produces delayed, persistent perturbations of emotional behaviors in mice. J Neurosci 28: 199-207.

Ansorge MS, Zhou M, Lira A, Hen R, Gingrich JA (2004). Early-life blockade of the 5-HT transporter alters emotional behavior in adult mice. Science 306: 879-881.

Bessa JM, Ferreira D, Melo I, Marques F, Cerqueira JJ, Palha JA et al (2008). The mood-improving actions of antidepressants do not depend on neurogenesis but are associated with neuronal remodeling. Mol Psychiatry advance online publication 4 November 2008.

Birmaher B, Ryan ND, Williamson DE, Brent DA, Kaufman J, Dahl RE et al (1996). Childhood and adolescent depression: a review of the past 10 years. Part I. J Am Acad Child Adolesc Psychiatry 35: 1427-1439.

Bolo NR, Hode Y, Nedelec JF, Laine E, Wagner G, Macher JP (2000). Brain pharmacokinetics and tissue distribution in vivo of fluvoxamine and fluoxetine by fluorine magnetic resonance spectroscopy. Neuropsychopharmacology 23: 428-438.

Borsini F, Podhorna J, Marazziti D (2002). Do animal models of anxiety predict anxiolytic-like effects of antidepressants? Psychopharmacology (Berl) 163: 121-141.

Carlson S, Willott JF (1998). Caudal pontine reticular formation of C57BL/6J mice: responses to startle stimuli, inhibition by tones, and plasticity. J Neurophysiol 79: 2603-2614.

Cases O, Seif I, Grimsby J, Gaspar P, Chen K, Pournin S et al (1995). Aggressive behavior and altered amounts of brain serotonin and norepinephrine in mice lacking MAOA. Science 268: $1763-1766$.

Cases O, Vitalis T, Seif I, De Maeyer E, Sotelo C, Gaspar P (1996). Lack of barrels in the somatosensory cortex of monoamine oxidase A-deficient mice: role of a serotonin excess during the critical period. Neuron 16: 297-307.

Chen ZY, Jing D, Bath KG, Ieraci A, Khan T, Siao CJ et al (2006). Genetic variant BDNF (Val66Met) polymorphism alters anxietyrelated behavior. Science 314: 140-143.

Czeh B, Michaelis T, Watanabe T, Frahm J, de Biurrun G, van Kampen $M$ et al (2001). Stress-induced changes in cerebral metabolites, hippocampal volume, and cell proliferation are prevented by antidepressant treatment with tianeptine. Proc Natl Acad Sci USA 98: 12796-12801.

Dulawa SC, Hen R (2005). Recent advances in animal models of chronic antidepressant effects: the novelty-induced hypophagia test. Neurosci Biobehav Rev 29: 771-783.

Dulawa SC, Holick KA, Gundersen B, Hen R (2004). Effects of chronic fluoxetine in animal models of anxiety and depression. Neuropsychopharmacology 29: 1321-1330.

Gould E, Tanapat P, Rydel T, Hastings N (2000). Regulation of hippocampal neurogenesis in adulthood. Biol Psychiatry 48: 715-720.

Gross C, Zhuang X, Stark K, Ramboz S, Oosting R, Kirby L et al (2002). Serotonin1A receptor acts during development to establish normal anxiety-like behaviour in the adult. Nature 416: 396-400.

Hammad TA, Laughren T, Racoosin J (2006). Suicidality in pediatric patients treated with antidepressant drugs. Arch Gen Psychiatry 63: 332-339.

Henderson ND, Turri MG, DeFries JC, Flint J (2004). QTL analysis of multiple behavioral measures of anxiety in mice. Behav Genet 34: 267-293.

Henry ME, Schmidt ME, Hennen J, Villafuerte RA, Butman ML, Tran $\mathrm{P}$ et al (2005). A comparison of brain and serum pharmacokinetics of R-fluoxetine and racemic fluoxetine: a 19F MRS study. Neuropsychopharmacology 30: 1576-1583.

Hirano K, Kimura R, Sugimoto Y, Yamada J, Uchida S, Kato Y et al (2005). Relationship between brain serotonin transporter binding, plasma concentration and behavioural effect of 
selective serotonin reuptake inhibitors. Br J Pharmacol 144: 695-702.

Holick KA, Lee DC, Hen R, Dulawa SC (2008). Behavioral effects of chronic fluoxetine in $\mathrm{BALB} / \mathrm{cJ}$ mice do not require adult hippocampal neurogenesis or the serotonin $1 \mathrm{~A}$ receptor. Neuropsychopharmacology 33: 406-417.

Lundmark J, Reis M, Bengtsson F (2001). Serum concentrations of fluoxetine in the clinical treatment setting. Ther Drug Monit 23: 139-147.

Maciag D, Simpson KL, Coppinger D, Lu Y, Wang Y, Lin RC et al (2006). Neonatal antidepressant exposure has lasting effects on behavior and serotonin circuitry. Neuropsychopharmacology 31: 47-57.

Malberg JE, Eisch AJ, Nestler EJ, Duman RS (2000). Chronic antidepressant treatment increases neurogenesis in adult rat hippocampus. J Neurosci 20: 9104-9110.

March J, Silva S, Petrycki S, Curry J, Wells K, Fairbank J et al (2004). Fluoxetine, cognitive-behavioral therapy, and their combination for adolescents with depression: treatment for adolescents with depression study (TADS) randomized controlled trial. JAMA 292: 807-820.

Meyer JH, Wilson AA, Sagrati S, Hussey D, Carella A, Potter WZ et al (2004). Serotonin transporter occupancy of five selective serotonin reuptake inhibitors at different doses: an [11C]DASB positron emission tomography study. Am J Psychiatry 161: 826-835.

Noorlander CW, Ververs FF, Nikkels PG, van Echteld CJ, Visser GH, Smidt MP (2008). Modulation of serotonin transporter function during fetal development causes dilated heart cardiomyopathy and lifelong behavioral abnormalities. PLOS ONE 3: e2782.

Norcross M, Poonam M, Enoch AJ, Karlsson RM, Brigman JL, Cameron HA et al (2008). Effects of adolescent fluoxetine treatment on fear-, anxiety- or stress-related behaviors in C57BL/6J or BALB/ cJ mice. Psychopharmacology (Berl) 200: 413-424.

Orsulak PJ, Kenney JT, Debus JR, Crowley G, Wittman PD (1988). Determination of the antidepressant fluoxetine and its metabolite norfluoxetine in serum by reversed-phase HPLC with ultraviolet detection. Clin Chem 34: 1875-1878.

Popa D, Lena C, Alexandre C, Adrien J (2008). Lasting syndrome of depression produced by reduction in serotonin uptake during postnatal development: evidence from sleep, stress, and behavior. J Neurosci 28: 3546-3554.

Prut L, Belzung C (2003). The open field as a paradigm to measure the effects of drugs on anxiety-like behaviors: a review. Eur J Pharmacol 463: 3-33.

Rauschecker JP (1999). Auditory cortical plasticity: a comparison with other sensory systems. Trends Neurosci 22: 74-80.

Reif A, Fritzen S, Finger M, Strobel A, Lauer M, Schmitt A et al (2006). Neural stem cell proliferation is decreased in schizophrenia, but not in depression. Mol Psychiatry 11: 514-522.

Rygula R, Abumaria N, Domenici E, Hiemke C, Fuchs E (2006). Effects of fluoxetine on behavioral deficits evoked by chronic social stress in rats. Behav Brain Res 174: 188-192.

Silverstone PH (2004). Qualitative review of SNRIs in anxiety. J Clin Psychiatry 65(Suppl 17): 19-28.

Strauss WL, Unis AS, Cowan C, Dawson G, Dager SR (2002). Fluorine magnetic resonance spectroscopy measurement of brain fluvoxamine and fluoxetine in pediatric patients treated for pervasive developmental disorders. Am J Psychiatry 159: 755-760.

Tatapudy S, Bruening S, Gleason G, Toth M (2008). Validation and use of a computer-assisted counting procedure to quantify BrdU-labeled proliferating cells in the early postnatal mouse hippocampus. J Neurosci Methods 172: 173-177.

Vollmayr B, Simonis C, Weber S, Gass P, Henn F (2003). Reduced cell proliferation in the dentate gyrus is not correlated with the development of learned helplessness. Biol Psychiatry 54: 1035-1040.

Wang PS, Simon G, Kessler RC (2003). The economic burden of depression and the cost-effectiveness of treatment. Int J Methods Psychiatr Res 12: 22-33.

Wilens TE, Cohen L, Biederman J, Abrams A, Neft D, Faird N et al (2002). Fluoxetine pharmacokinetics in pediatric patients. J Clin Psychopharmacol 22: 568-575.

Zazpe A, Artaiz I, Labeaga L, Lucero ML, Orjales A (2007). Reversal of learned helplessness by selective serotonin reuptake inhibitors in rats is not dependent on 5-HT availability. Neuropharmacology 52: 975-984.

Supplementary Information accompanies the paper on the Neuropsychopharmacology website (http://www.nature.com/npp) 